\title{
Students' evaluation of digital information: The role teachers play and factors that influence variability in teacher behaviour
}

\author{
Ida K. R. Hatlevik \\ University of Oslo, Norway \\ Ove E. Hatlevik \\ OsloMet - Oslo Metropolitan University, Norway
}

Author Note

Ida. K. R., Department of Teacher Education and School Research (ILS), Faculty of Educational Sciences, University of Oslo; Ove E. Hatlevik, Faculty of Education and International Studies, OsloMet - Oslo Metropolitan University.

Correspondence concerning this article should be addressed to Ida. K. R. Hatlevik, Department of Teacher Education and School Research (ILS), Faculty of Educational Sciences, University of Oslo. Postbox 1099 Blindern, NO-0317 Oslo, Norway. E-Mail: i.k.r.hatlevik@ils.uio.no 


\title{
Students' evaluation of digital information: The role teachers play and factors that influence variability in teachers behaviour
}

\begin{abstract}
Students deal with large amounts of digital information each day, which, clearly, they need to be able to evaluate. Teachers can play pivotal roles in fostering students' evaluation of digital information. Here, using Norwegian data drawn from 1,158 teachers in 116 schools, we report on an investigation into ways in which variables interact and influence such fostering. Overall, most teachers are found to report that student skills in evaluating digital information are a focus of instruction, especially in respect of the evaluation of accuracy, credibility and relevance. In addition, the results show moderate to high positive associations among the use of information communication and technology (ICT) in teaching generally, ICT self-efficacy for instructional purposes, collegial collaborations and the teacher fostering (of students' capabilities to evaluate digital information). Finally, a structural equation modeling (SEM) analysis indicates that the use of ICT in teaching and ICT self-efficacy for instructional purposes are positive predictors of variations in teaching practices related to fostering students' abilities to evaluate digital information.
\end{abstract}

Keywords: Fostering students' evaluation of digital information, ICT self-efficacy, use of ICT, collegial collaboration, Norwegian teachers.

\section{Introduction}

We live in a digital world where we are bombarded with news and information. Thus, it is an important skill to be able to sort out reliable information. Capability to evaluate information is an important skill for the individual, so he or she does not build a life on false premises. Furthermore, it is important for democracy and the society as a whole to have well informed citizens who are not easily being misled by "alternative facts" and "fake news". Teachers can play an important role in enhancing students' capabilities to evaluate digital information (Walraven, Brand-Gruwel and Boshuizen, 2013); however, there are variations among teachers regarding their use of ICT in teaching (European Commission, 2013; Fraillon, Ainley, Schulz, Friedman, \& Gebhardt, 2014; Gill et al., 2015; Tondeur et al., 
2015). This article used the International Computer and Information Literacy Study (ICILS) 2013 to investigate Norwegian schoolteachers' fostering of students' ability to evaluate digital information, and possible related variables.

Efficient digital skills “include developing digital judgement by acquiring knowledge and good strategies for the use of the Internet" (Norwegian Directorate for Teaching and Instruction, 2012, p. 12); however, there are reasons to be concerned about whether students are able to assess the quality of digital information (Puustinen \& Rouet, 2009). Recent studies have identified that students tend to favour convenience with little focus on the evaluation of digital information (Biddix, Chung, \& Park, 2011; Blikstad-Balas, 2016; Metzger, 2007; Walraven, Brand-Gruwel, \& Boshuizen, 2009). Furthermore, there seems to be a discrepancy between the online sources students trust and the online sources they use (Biddix et al., 2011; Hatlevik, 2016; Walraven et al., 2009). Overall, it seems that many students require support from their teachers to develop the capability to evaluate digital information. Thus, the ways teachers' foster students' evaluation of digital information is an important area that should be investigated.

Furthermore, previous research has indicated that there are variations among teachers regarding their confidence in their ability to use ICT efficiently during instruction (Haydn, 2014), and that collegial cooperation is crucial to teachers' efficacy beliefs and to their actual teaching practices (Goddard, Goddard, \& Tschannen-Moran, 2007). This paper examines the extent to which teachers indicated giving emphasise to develop students' capabilities to evaluate the quality of digital information. The paper also addresses whether there are specific circumstances, i.e. teachers' ICT self-efficacy for instructional purposes, ICT use in teaching practice and collegial collaboration when using ICT in teaching and learning, which could explain the variations in teachers' 
approaches to improving students' abilities to evaluate digital information. In the following sections, the studies used to formulate the research questions that were explored and the hypotheses that were tested are described.

\subsection{Evaluating Digital Information}

Students often use online sources when searching for information (Biddix et al., 2011; Metzger \& Flanagin, 2013). A disadvantage of online digital resources and information is the uncertainty regarding editorial reviews (Kubiszeqski, Noorderwier \& Costanza, 2011) or other ways to check the quality of information (Walraven et al., 2009).

Metzger and Flanaging (2013) emphasised the importance of developing criteria that should be used to conduct a proper evaluation of digital information. Metzger (2007) recommended that students should examine the accuracy, authority, objectivity, currency and coverage of online information. Accuracy refers to determining whether precise and correct information is found. Authority involves the author of information, e.g. whether the author has recognised knowledge about the topic and whether the author is supported by other credible sources. Objectivity refers to the purpose of publishing information and determining whether the information is unbiased and presents facts. Currency is related to whether information is outdated or updated. Coverage involves checking information to ensure that it is coherent and comprehensive (Metzger \& Flanagin, 2013).

Our study is a secondary analysis of already existing data (ICILS 2013). The ICILS 2013 was not designed to specifically measure exactly the same five criteria that Metzger recommended (2006; 2013). Instead, the ICILS framework (Fraillon, Schulz \& Ainley, 2013) includes measuring seven different aspects to describe ICT capabilities for students. One of these aspects, "Accessing and evaluating information", involves 
evaluating digital information involves evaluating digital information by focusing on relevance, credibility, accuracy and exploring a range of digital resources. "Accessing and evaluating information" is described as the "investigative processes that enable a person to find, retrieve, and make judgments about the relevance, integrity, and usefulness of computer-based information" (Fraillon et al., 2014, p. 17). This is an important aspect of computer and information literacy because it deals with how students are capable of evaluating digital information and what the teachers are reporting about giving emphasise to develop these capabilities.

Nevertheless, some students experience difficulties using some of these criteria on their own. Recent research showed that students consider the validity of the information they find online to different degrees (Puustinen \& Rouet, 2009). On one hand, there seems to be a group of students with thoughtful and appropriate approaches to evaluating information (Hatlevik, Tømte, Skaug, \& Ottestad, 2011). On the other hand, many students seem to use insignificant criteria in their evaluation of online information (Metzger, 2007). Secondary school students tend to focus on content and form instead of using other criteria (Mason, Junyent and Tornatora, 2014). Many students favour convenience and use few sources, e.g. conducting a search with Google before using Wikipedia to find information (Blikstad-Balas, 2015; Hatlevik et al., 2011). It appears that students tend to use readily available sources rather than the sources they judge most credible (Hatlevik, 2016). Recent research has also shown that students have difficulties dealing with inconsistent information across websites and identifying the characteristics of the most credible websites (Mason et al., 2014). Furthermore, research has indicated that source evaluation is difficult for students (Puustinen \& Rouet, 2009) and that they therefore need support and guidance (Metzger \& Flanagin, 2013; Walraven et al., 2013). Based on the results of these studies, many students require 
assistance in developing the capability to evaluate the relevance, credibility and accuracy of digital information. Students also require guidance to understand the reasons they should explore a range of digital sources.

Walraven et al. (2013) developed a programme used to guide students. They conducted research on students and their teachers who had access to this programme. The study showed that the programme could improve students' evaluation behaviours and examination scores. Thus, it would be interesting to investigate the extent to which teachers facilitate students' evaluation of digital information. Furthermore, it would be useful to identify variables that can explain variations in teachers' approaches to facilitating students' capabilities to evaluate digital information. Previous research has indicated that both teachers' ICT self-efficacy for instructional purposes (Scherer \& Siddiq, 2015) and collegial collaboration (Tondeur et al., 2012) may have significant impacts on how and to what extent teachers use ICT in practice. In the following sections, research related to teachers' self-efficacy, their use of ICT and collegial collaboration is discussed.

\subsection{ICT Self-Efficacy for Instructional Purposes}

Self-efficacy is derived from an assumption that people are active agents capable of shaping the content and directions of their learning and achievements (Sáinz \& Eccles, 2012). Self-efficacy involves the perceived expectations of one's capability to solve a problem, finish a task or accomplish a goal (Bandura, 1997, 2006). It is also important when choosing activities as well as for performance because being confident in the capability to obtain a goal could lead to a willingness to apply effort and persistence to the process (Bandura, 2006). Recent research emphasised the importance of teachers' self-efficacy in general (Christophersen et al., 2016; Klassen \& Chiu, 2010). One example is that self-efficacy has a positive correlation with higher levels of commitment to 
teaching and with more effective teaching practices (Skaalvik \& Skaalvik, 2010; VielRuma, Houchins, Jolivette, \& Benson, 2010). Thus, it is important to investigate teachers' self-efficacy in using ICT for teaching purposes when investigating teachers' actual use of ICT in practice (Krumsvik, 2011).

Bandura (1997) asserts that self-efficacy is context and domain specific (i.e. not a global trait) and that the level of self-efficacy with regard to a specific type of task or behavior is affected by individuals' perception of mastery of that task and the interpretation of feedback on their performance. In this study, the focus was ICT selfefficacy for instructional purposes. Recent research showed a positive relationship between ICT-related self-efficacy and achievements in ICT (Abele \& Spurk, 2009; Broos \& Roe, 2006; Yang \& Cheng, 2009). The concept of self-efficacy is also important when studying teachers' use of ICT during instruction (Fanni, Rega, \& Cantoni, 2013; Krumsvik, 2014; Tondeur, Hermans, van Brak, \& Valcke, 2008).

\subsection{Use of ICT in Teaching}

Findings from different countries show that teachers' use of ICT for teaching and learning purposes is below expectations (European Commission, 2013; Fraillon et al., 2014; Gill, Dalgarno, \& Carlson, 2015; Tondeur, Aesaert, Pynoo, van Braak, Fraeyman, \& Erstad, 2015). Further, there are also findings that show variations in how efficient teachers use new technology in their own practice (Fraillon et al., 2014; Haydn, 2014). Moreover, Hammond, Reynolds, and Ingram (2011) examined reasons that teachers use ICT, and they discovered a relationship between lower levels of ICT self-efficacy and less frequent use of ICT. Recent research showed a positive relationship between selfefficacy in using digital tools and the use of ICT for teaching purposes (Teo, 2014). Increased levels of computer self-efficacy can lead to higher levels of confidence in using ICT efficiently during instruction (Fanni et al., 2013). So, Choi, Lim and Xiong (2012) 
reported that teacher students' use of computers was related to computer self-efficacy. In line with the previous research findings presented in paragraph 1.2 and 1.3, it was expected that teachers' use of ICT in their teaching practice would be closely related to their ICT self-efficacy for instructional purposes (hypothesis 1, Table 1). In addition, we will argue that it is also reasonably to expect that teachers who actually use ICT in their teaching practice, to a greater extent foster students' evaluation of digital information than those who seldom uses ICT in teaching. In theory, teachers could teach their students about the importance of evaluation of digital information without actually using ICT in their own teaching of their students. In practice, however, it seems more likely that the issue of developing students' ability to evaluate digital information first and foremost occurs when the teachers engage their students in ICT-based learning activities. Therefore, we expect that teachers' use of ICT in their teaching practice would be positively related to their emphasis on fostering students' capabilities in evaluating digital information (hypothesis 2, Table 1). Furthermore, as previously mentioned, research indicate that teachers' ICT self-efficacy for instructional purposes are related to their actual use of ICT in teaching practice, and we find it therefore logical to expect that teachers' ICT self-efficacy for instructional purposes would be positively related to fostering students' competence in evaluating digital information (hypothesis 3, Table 1). Hypothesis 3 is somewhat exploratory since there are, to our knowledge, no previous research on the relationship between teachers' ICT self-efficacy for instructional purposes and their emphasis on fostering students' capabilities in evaluating digital information. 


\subsection{Collegial Collaboration}

Previous studies have indicated that collegial collaboration is an important aspect of teachers' professional development (Goddard, Goddard, \& Tschannen-Moran, 2007; Forte \& Flores, 2014) and teacher efficacy (Goddard et al., 2007; Caspersen \& Raaen, 2014). This implies that teachers' perceptions of collegial collaboration when using ICT in teaching and learning is expected to be closely associated with their ICT self-efficacy for instructional purposes (hypothesis 4, Table 1). In addition, previous studies have indicated that collegial collaboration are influencing their actual teaching practice and student achievement (Goddard et al., 2007). Results from the TALIS 2013 study showed that Norwegian teachers are requesting assistance in developing their professional digital competence (OECD, 2014). Previous studies have identified an association between facilitating teachers' use of ICT and their professional digital literacy development (Tondeur et al., 2012). Tondeur et al. (2012) underscored that learning from peers and collegial collaboration can assist pre-service teachers' implementation of ICT in practice. In addition, research shows that teachers prefer informal methods of training when learning how to use ICT and in developing their digital competence (Wastiau et al., 2013). Furthermore, teachers prefer developing digital competence through collaboration with other teachers (Bacigagulpo \& Cachia, 2011) over participating in external courses (Egeberg et al., 2011), and they also prefer training that is related to classroom settings (Balanskat, Blamire, \& Kefala, 2006). This indicates that collegial collaboration provides informal opportunities for teachers to learn from each other and that this type of learning opportunity may improve instruction approaches and foster teacher self-efficacy. This implies that teachers' perceptions of collegial collaboration when using ICT in teaching and learning is expected to be closely associated with their use of ICT in practice (hypothesis 5, Table 1). Collegial 
collaboration entails that the participants share knowledge and ideas. Hence, collegial collaboration may contribute so that the individual teachers become more aware of the importance of fostering students' ability to evaluate online information. This assumption imply that teachers' perceptions of collegial collaboration when using ICT in teaching and learning is expected to be closely associated with fostering students' evaluation of digital information (hypothesis 6, Table 1).

\subsection{Research Questions and Hypotheses}

The main aims of the present study were to examine teachers' fostering of students' evaluation of digital information and to identify variables that can explain variations in teachers' approaches to fostering students' evaluation of digital information. The objective of this study was to answer two research questions (RQ): (RQ1): Which approaches do teachers use to foster students' evaluation of digital information?

(RQ2): What are the relationships between teachers' use of ICT in teaching, their ICT self-efficacy for instructional purposes, collegial collaboration involving ICT and their approaches to fostering students' evaluation of digital information?

Table 1 lists the six hypotheses regarding the relations between teachers' use of ICT, ICT self-efficacy for instructional purposes, collegial collaboration and fostering students' evaluation of digital information. 


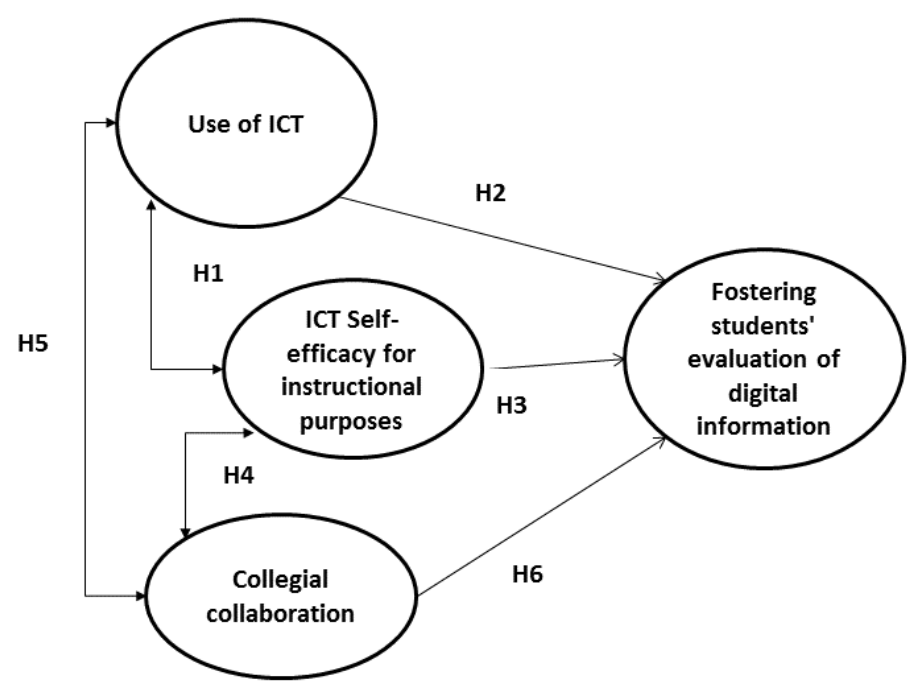

Figure 1: A model of the hypothesized relationship between teachers' use of ICT, ICT selfefficacy for instructional purposes, collegial collaboration and fostering students' evaluation of digital information.

A model (Figure 1) has been developed to describe the hypothesised associations between the concepts in RQ2 (see Table 1). The model shows that teachers' use of ICT in teaching, their ICT self-efficacy for instructional purposes and collegial collaboration involving ICT are expected to be related, and these variables can explain variations in teachers' emphasis on fostering students' ability to evaluate digital information.

\section{Methods}

\subsection{Participants and Procedure}

The ICILS study consist of data from 21 countries or educational systems. A twostep procedure was used to sample the teachers from each of the participating countries. First, 150 schools with grade 9 were randomly selected to participate in the study. There are two different types of Norwegian schools with $9^{\text {th }}$ grade. The lower 
secondary schools with $8^{\text {th }}-10^{\text {th }}$ grade and the combined schools with $1^{\text {st }}$ to $10^{\text {th }}$ grade. Our data consists of responses from teachers who teaches $9^{\text {th }}$ grade students in both of these types of schools. The average age of the students was 14.8 years one the time of the sampling (Fraillon et al., 2014, p. 96). Second, based on the size of the school and the number of teachers in the school, between 15 and 20 teachers were selected from each school. The total number of responses in Norway was 1.158 teachers from 116 schools. The response rate at the school level was $79 \%$.

\subsection{Instruments}

The teachers completed an online questionnaire that mainly focused on their belief about ICT and how they used ICT in their classrooms. We have selected questions related to the topics in the model (Figure 1). All the questions and statements are presented in Table 2 along with information about descriptive statistics and univariate normality as well as the factor loadings obtained from the latent variable models for the scales.

Fostering students' evaluation of digital information. The teachers gave response to four statements to indicate how much emphasise they had given to develop students capabilities to check the relevance, credibility and accuracy of digital information (Fraillon et al., 2014, p. 215), in addition to using information from various resources. The corresponding response categories were: $1=$ no emphasis, $2=$ a little emphasis, $3=$ some emphasis and $4=$ strong emphasis.

Use of ICT. Seven questions were asked related to the extent to which teachers use ICT in teaching. A three-point rating scale was used: $1=$ Never, $2=$ Sometimes and 3 $=$ Often. 
ICT self-efficacy for instructional purposes. Three statements were used to identify teachers' confidence in using ICT for instructional purposes. A three-point scale was used: 1 = I do not think I could do this, $2=\mathrm{I}$ could work out how to do this and $3=\mathrm{I}$ know how to do this.

Collegial collaboration. This concept was measured using two statements regarding the way teachers collaborate with their colleagues when using ICT in teaching and learning practices. The corresponding response categories were: 1 = strongly disagree, 2 = disagree, 3 = agree and 4 = strongly agree.

-----Table 2 -----

\subsection{Analytical Strategy}

Before addressing the research questions, the data were analysed to determine their descriptive statistics (means and standard deviations) and measures of univariate normality (skewness and kurtosis). To answer RQ1, the items used to measure the construct labelled 'fostering students' evaluation of digital information' were analysed.

Structural equation modeling (SEM) was used to examine RQ2 by testing the assumed relationship between the variables (Table 1) presented in the model (Figure 1). SEM provides a methodological approach to simultaneously analyse both the measurement models of the constructs and the structural relations between the latent variables (Kline, 2010). Moreover, SEM enables researchers to evaluate the fit of a hypothesised model and to therefore obtain information about the extent to which the data represent the assumed relationships (Brown, 2006).

To evaluate the goodness-of-fit of the model (Figure 1), the chi-square test, the Comparative Fit Index (CFI), the Tucker-Lewis Index (TLI) and the Root Mean Square Error of Approximation (RMSEA) were used (Brown, 2006; Kline, 2010). In addition, for 
the categorical data for ICT self-efficacy for instructional purposes, the Weighted Root Mean Square Residual (WRMR) was used (Yu, 2002). There are some guidelines for the evaluation of the fit indices (Marsh, Hau, \& Wen, 2004). Levels of the CFI and TLI equal to or above 0.95 and an RMSEA below or equal to 0.08 (Marsch et al., 2004) indicate a good model fit. Levels of a WRMR close to or below 1.00 indicate a good model fit (Yu, 2002). The full-information-maximum procedure in Mplus was used for missing values.

\section{Results}

\subsection{Statistics}

Information about the teachers' age and gender is presented in Table 3. Of the participants, $64 \%$ were female, and $10 \%$ of the respondents were below 30 years old. The two largest age groups in the study were teachers between $30-39$ years old (30 \%) and teachers between 40-49 years old (27\%). Of the teachers, $19 \%$ were between 50 59 years old, and $13 \%$ were 60 years or older.

The values for mean, standard deviation, skewness and kurtosis are presented in Table 2. The levels of skewness and kurtosis were acceptable for the items used to measure the Use of ICT in teaching, Collegial collaboration and Fostering of students' evaluation of digital information. One item (preparing lessons that involve the use of ICT by students) that was used to measure ICT self-efficacy for instructional purposes had higher levels of both skewness and kurtosis. On this specific statement $90 \%$ of the teachers answered that I know how to do this, and only $1 \%$ answered that I do not think I could do this. All items used to measure ICT self-efficacy for instructional purposes were therefore treated as categorical data in the analyses. The responses were recoded into two categories: 1 = I do not know how to do it or $2=\mathrm{I}$ do know how to do it. The first category included responses to both original ratings on 1 (I do not think I could do 
this) and 2 (I could work out how to do this), which is one way to conduct an analysis when the data are not normally distributed.

----Table 3 ----

\subsection{Research Question 1- Percentage}

The first research question involved teachers' fostering students' evaluation of digital information. Approximately $71 \%$ of the teachers agreed with teaching ways to evaluate 'the relevance of digital information', and $72 \%$ emphasised checking 'the credibility of digital information' (see Table 3). More than $66 \%$ of the teachers focused on 'validating the accuracy of digital information', and approximately $54 \%$ emphasised that students explored a range of digital resources.

Additional analyses were conducted to investigate whether there were major differences between schools. The analyses of the intraclass correlation showed that most variations in fostering students' evaluation of digital information were within schools (98.6 \% - 99.8\%), and less than $1.5 \%$ of the variations were between schools, indicating that the schools were quite similar in terms of the ways they fostered students' evaluation of digital information; however, there were differences between the teachers in the study regarding the questions about fostering the evaluation of digital information. Therefore, individual characteristics were carefully examined by conducting analyses of gender differences. Females reported higher levels of fostering the evaluation of digital information compared with males (Table 4). The results indicated significant but minor gender differences in terms of effect size. 


\subsection{Research Question 2 - Measurement Model}

Research question 2 involved the relationships between teachers' use of ICT, their ICT self-efficacy for instructional purposes, collegial collaboration involving ICT and fostering students' evaluation of digital information, which were tested using SEM. The tested model had a reasonable good fit in which chi-square $(115)=318.81, p<.01$, $\mathrm{CFI}=0.962, \mathrm{TLI}=0.953, \mathrm{RMSEA}=0.044,90 \%-\mathrm{CI} \mathrm{RMSEA}=[0.039,0.050]$ and $\mathrm{WRMR}=$ 0.955 .

Item loadings can be used to examine how items reflect a construct. Item loadings above 0.60 are desirable, but items with lower loadings can also provide relevant information about constructs. All item loadings for the evaluation of digital information and ICT self-efficacy were 0.70 or above (Table 2). The item loadings for collegial collaboration were above 0.60 . Three out of seven item loadings for the use of ICT were 0.60 or above, three item loadings were between 0.50 and 0.60 , and one item loading was 0.48 . Overall, it seems that most items are working resonably well.

The correlation matrix (Table 4) showed positive associations between all latent variables. The results from the SEM analysis showed a positive relationship between teachers' use of ICT, their ICT self-efficacy for instructional purposes and collegial collaboration. Further, the results showed that teachers ICT self-efficacy for instructional purposes $\left(\beta=0.15^{* *}\right)$ and their use of ICT $\left(\beta=0.49^{* *}\right)$ had a positive, direct association with fostering students' evaluation of digital information. The model explained $34 \%$ of the variation in teachers' emphasis on fostering students' ability to evaluate digital information. 


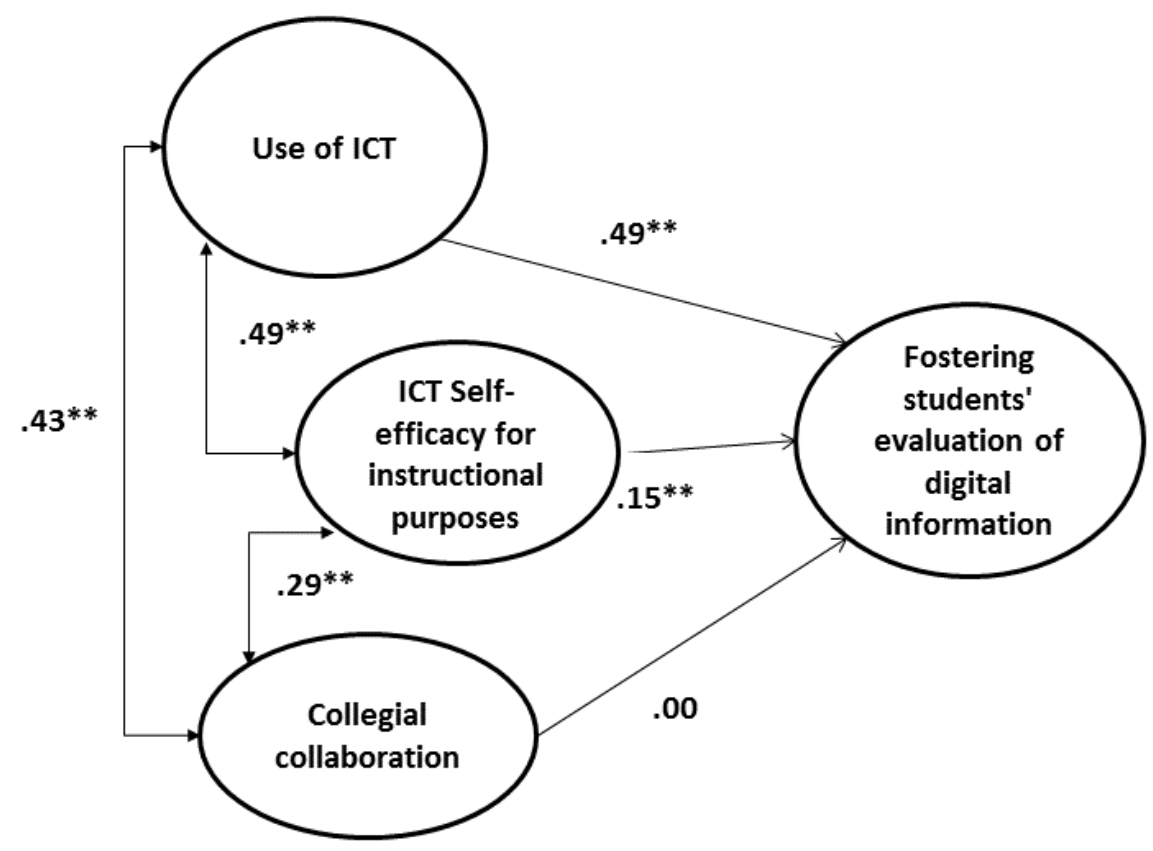

Figure 2: The relationship between teachers' use of ICT, ICT self-efficacy for instructional purposes, collegial collaboration and fostering students' evaluation of digital information $\left({ }^{* *} p<.01\right)$.

\section{Discussion}

Research has shown that students generally require assistance from teachers to develop the capability to evaluate digital information. The critical evaluation of information is a skill that must be developed (Biddix et al., 2011), and students need training and instruction criteria for conducting evaluations (Mason et al., 2014). This study examined teachers' approaches to fostering students' capabilities to evaluate digital information (RQ1). The majority of teachers (approximately 7 out of 10) reported giving emphasis to developing students' capabilities to judge the accuracy, credibility and relevance of digital information. This is in line with the suggestions from Metzger and Flanagin (2013) that students should be provided with criteria they can use when searching for and checking information. Walgraven et al. (2013) showed that it is 
possible for teachers to influence how students evaluate information. They recommended linking criteria for checking and evaluating information with specific subjects or tangible domains. The contextualisation to subjects or domains can help students determine how to use the criteria.

In contrast, a markedly lower proportion, only approximately half of the teachers, reported giving emphasis to developing students' capabilities to explore and use information from a range of different resources. This is worth discussing because many Norwegian students are time-effective (Frønes, Narvhus and Jetne, 2011) and are selecting information from a few sources (Blikstad-Balas, 2015; Hatlevik et al., 2011). As shown by Mason et al. (2014), students find it especially difficult to use information from various sources and to compare the content. Using information from multiple sources requires that students consider each source as well as the information each source provides, meaning that students must evaluate the credibility, accuracy and relevancy of the information found in the digital sources as well as consider the reputation of each source. There are several competence goals in the national curriculum for primary and secondary schools related to evaluating information (Frønes et al. 2011). Because many students struggle with (Puustinen \& Rouet, 2009) and need help developing the capability to explore, evaluate and use multiple sources of information (Metzger \& Flanagin, 2013; Walraven et al., 2013), it is especially problematic that such a small proportion of teachers report helping students develop this skill. There are free guideline materials on this topic for both lower secondary schools and upper secondary schools (Norwegian Centre for ICT in Education, 2017); however, based on the results of this study, there is a need for teachers to be provided with more information about these guidelines, particularly those related to the importance of promoting students' capability to evaluate multiple sources of digital 
information. Nevertheless, these four different capabilities of evaluating digital information are related and partly overlapping. When checking a resource for credibility a person could look at the authority of the author/publisher, check the accuracy of the information and examine if the information is in line with other sources.

The second research question involved understanding the variables that were expected to explain teachers fostering students' evaluation of digital information. It is encouraging that the SEM analysis indicate that the teachers who reported using ICT in education also to a large extent reported giving emphasis to fostering students' ability to evaluate digital information, thus corroborating hypothesis 2 . This might indicate that the teachers who used ICT during instruction believe it is important to teach students to become critical users of digital information. This group of teachers probably has a more nuanced view of the various types of information sources available on the Internet than teachers who do not use ICT during instruction, and they are thus more likely to recognise the need for students to develop this type of capability to evaluate digital information. It can be assumed that teachers who are less frequent users of ICT during instruction are less familiar with the challenges related to the use of digital information. Another explanation might be that if ICT is not used during instruction, the challenges related to students' use of digital information will not be addressed. Nevertheless, this study indicated that promoting and facilitating teachers' use of ICT during instruction could indirectly contribute to teachers enhancing students' capability to evaluate digital information.

In addition, the SEM analysis indicated that teachers' ICT self-efficacy for instructional purposes is linked to both their use of ICT for school activities (hypothesis 1) and to reporting fostering students capability to evaluate digital information (hypothesis 3). The positive relationship between self-efficacy and the use of ICT is in 
line with recent studies (Fanni et al., 2013; Hammond et al., 2011; Teo, 2014). Bandura (1997) pointed out that teachers' self-efficacy is not a constant, but it is affected by factors such as mastery experiences, vicarious experiences and feedback from significant others. Banduras' theory indicates that there is a positive relationship, and perhaps an interaction, between teachers' ICT-self-efficacy for instructional purposes and having positive experiences from using ICT in practice. In line with Banduras' statement, the results indicated that developing and supporting teachers' confidence in using ICT in practice could be an efficient way to promote their use of ICT, which could thereby foster students' evaluation of digital information. Thus, there is a need for studies that focus on how teachers' ICT self-efficacy for instructional purposes is affected by support and facilitation from school management, collegial collaboration and general ICT self-efficacy (not teaching specific but confidence in using ICT in general).

Previous research has revealed that teachers prefer to develop digital competence through collaboration with other teachers (Bacigaguplo \& Cachia, 2011; Egeberg et al., 2011). The results of this study corroborate the results of Goddard et al.'s (2007) study, which showed that collegial collaboration is associated with teaching practices. The SEM-analysis showed that collegial collaboration has a substantial association with teachers' ICT self-efficacy for instructional purposes as well as their use of ICT during instruction. This result indicates that encouraging and facilitating opportunities for teachers to engage in collegial collaboration may be an effective way for school management to enhance teachers' use of ICT in practice.

The results of this study are largely in line with those of previous research studies that have focused on the impact of one or two variables on either teachers' efficacy or teaching practices. In the SEM analysis, the ways several variables interact were examined, and the variance in the variable 'Fostering students' evaluation of digital 
information' was evaluated; however, this study has limitations, and the results of the SEM analysis should be considered tentative until replicated. This study is a crosssectional correlation analysis, which does not allow for testing causal relationships. The design of the ICILS 2013 does not make it possible to identify teachers and the students in the teachers' reference class. There is a need for other studies for example longitudinal studies or studies that connect the students with their own teachers, for example the TIMSS.

Omitted variables might also have influenced the explored model. For example, it could be interesting to include questions to teachers about their approaches to teach this topic (evaluation of digital resources), the relevance of this topic and their selfefficacy in evaluation of digital resources. In addition, the study did not identify whether there are age specific or subject specific characteristics related to whether the teachers reported fostering students' evaluation of digital information, which could be an interesting topic for further research.

\section{Concluding Remarks}

Exploring a range of different sources and evaluating their relevance, credibility and accuracy are important aspects of evaluating digital information. Although most teachers reported giving emphasise to fostering students' capabilities to evaluate digital information, a considerably lower proportion emphasised exploring a range of different sources. Why do some teachers emphasise this particular aspect to a lesser extent? Are they unfamiliar with the difficulties students have when using, evaluating and comparing the content of different sources? Does the importance of exploring a range of 
different sources need to be underscored more thoroughly in the guideline materials, or are many teachers unfamiliar with the guideline materials that exist?

Another conclusion is the positive association between teachers who reported using ICT during instruction and the fostering of students' evaluation of digital information. How can this be interpreted? Is it the use itself, or is it that by using ICT, teachers experience the need to check and evaluate digital information firsthand? In addition, there is a positive relationship between teachers' use of ICT and their instructional ICT self-efficacy. Thus, to better understand how to promote teachers' use of ICT during instruction, there is a need to provide information regarding ways to facilitate the development of teachers' ICT self-efficacy for instructional purposes. Overall, it seems that additional research on ways to support teachers' fostering of students' evaluation of digital information is needed.

\section{References}

Abele, A. E., \& Spurk, D. (2009). The longitudinal impact of self-efficacy and career goals on objective and subjective career success. Journal of Vocational Behavior, 74, 53-62.

Aesaert, K., van Nijlen, D., Vanderlinde, R., Tondeur, J., Devlieger, I., \& van Braak, J. (2015). The contribution of pupil, classroom and school level characteristics to primary school pupils' ICT competences: A performance-based approach. Computers \& Education, 87, 5569. dx.doi.org/10.1016/j.compedu.2015.03.014

Bandura, A. (1997). Self-efficacy: The exercise of control. NY: Freeman.

Bandura, A. (2006). Guide for constructing self-efficacy scales. In F. Pajares, \& T. Urdan (Eds.), Adolescence and education: Vol. 5. Self-efficacy and adolescence (pp. 307-337). Greenwich, CT: Information Age.

Balanskat, A., Blamire, R., \& Kefala, S. (2006). The ICT Impact Report. A Review of Studies of ICT Impact on Schools (Brussels, European Schoolnet).

Bacigagulpo, M., \& Cachia, R. (2011). Teacher Collaboration Networks in 2025. What is the Role of Teacher Networks for Professional Development in Europe? (Sevilla, JRC-IPTS). 
Blikstad-Balas, M. (2016). 'You get what you need': A study of students' attitudes towards using Wikipedia when doing school assignments. Scandinavian Journal of Educational Research, 60(6), 594-608. DOI: 10.1080/00313831.2015.1066428

Biddix, J.B., Chung, C.J., \& Park, H.W. (2011). Convenience or credibility? A study of college student online research behaviors. Internet and Higher Education, 14, 175-182.

Broos, A., \& Roe, K. (2006). The digital divide in the PlayStation generation: Self-efficacy, locus of control and ICT adoption among adolescents. Poetics, 34, 306-317.

Brown, T. A. (2006). Confirmatory factor analysis for applied research. London: The Guilford Press.

Caspersen, J., \& Raaen, F. D. (2014). Novice teachers and how they cope. Teachers and Teaching: Theory and Practice, 20, 189-211. doi:10.1080/13540602.2013.848570

Christophersen, K. A., Elstad, E., Turmo, A., \& Solhaug, T. (2016). Teacher education programmes and their contribution to student teacher efficacy in classroom management and pupil engagement. Scandinavian Journal of Educational Research, 60, 240-254.

Egeberg, G., Gudmundsdottir, G. B., Hatlevik, O. E., Ottestad, G., Skaug, J. H., \& Tømte, K. (2011). Monitor 2011. Skolens digitale tilstand. Oslo: Senter for IKT i utdanningen.

European Commission. (2013). Survey of schools: ICT in education. Benchmarking Access, Use and Attitudes to Technology in Europe's Schools. https://ec.europa.eu/digitalagenda/node/51275

Fanni, F., Rega, I., \& Cantoni, L. (2013). Using self-efficacy to measure primary school teachers' perception of ICT: Results from two studies. International Journal of Education and Development using Information and Communication Technology (IJEDICT), 9(1), 100-111.

Forte, A.M., \& Flores, M.A. (2014) Teacher collaboration and professional development in the workplace: A study of Portuguese teachers. European Journal of Teacher Education, 37(1), 91-105. DOI: 10.1080/02619768.2013.763791

Frønes, T.S., Narvhus, E.K. og Jetne, Ø. (2011): Kortrapport. Elever på nett. Digital lesing i PISA 2009 (Shortreport. Students on the internet: Digital reading in PISA 2009). Oslo: University of Oslo.

Fraillon, J., Schulz, W., \& Ainley, J. (2013). International Computer and Information Literacy Study 
assessment framework. Amsterdam, the Netherlands: International Association for the Evaluation of Educational Achievement (IEA).

Fraillon, J., Ainley, J., Schulz, W., Friedman, T., \& Gebhardt, E. (2014). Preparing for life in a digital age - The IEA international computer and information literacy study. International report. Amsterdam: IEA.

Gill, L., Dalgarno, B., \& Carlson, L. (2015). How does pre-service teacher preparedness to use ICTs for learning and teaching develop through their degree program? Australian Journal of Teacher Education, 40(1), 35-59.

Goddard, Y., Goddard, R. D., \& Tschannen-Moran, M. (2007). A theoretical and empirical investigation of teacher collaboration for school improvement and student achievement in public elementary schools. Teachers College Record, 109, 877-896.

Hargittai E., \& Shafer S. (2006). Differences in actual and perceived online skills: The role of gender. Social Science Quarterly, 87(2), 432-448. doi:10.1111/j.1540-6237.2006.00389.x

Hatlevik, O. E. (2016). Ninth graders' use of and trust in Wikipedia, textbooks, and digital resources from textbook publishers. In: E. Elstad (Ed.), Digital expectations and experiences in education (pp. 205-219). Oslo: Sense Publishers.

Hatlevik, O. E., Tømte, K., Skaug, J. H., \& Ottestad, G. (2011). Monitor 2010 - Discussion about ICT at school. Oslo: Norwegian Centre for ICT in Education.

Hammond, M., Reynolds, L. \& Ingram, J. (2011). How and why do student teachers use ICT? Journal of Computer Assisted Learning, 27, 191-203. doi: 10.1111/j.13652729.2010.00389.x

Haydn, T. (2014). How do you get pre-service teachers to become 'good at ICT' in their subject teaching? The views of expert practitioners. Technology, Pedagogy, and Education, 23(4), 455-569.

Klassen, R. M., \& Chiu, M. M. (2010). Effects on teachers' self-efficacy and job satisfaction: Teacher gender. Years of experience, and job stress. Journal of Educational Psychology, 101(3), 741-756.

Kline, R. B. (2010). Principles and practice of structural equation modeling (3rd ed.). New York, NY: Guilford Press.

Krumsvik, R. (2011). Digital competence in Norwegian teacher education and schools. Högre 
utbilding, 1, 39-51.

Krumsvik, R. J. (2014). Teacher educators' digital competence. Scandinavian Journal of Educational Research, 58(3), 269-280. doi:10.1080/00313831.2012.726273.

Kubiszeqski, I., Noorderwier, T., \& Costanza, R. (2011). Perceived credibility of Internet encyclopedias. Computers \& Education, 56, 659-667.

Lau, W. W. F., \& Yuen, A. H. K. (2015). Factorial invariance across gender of a perceived ICT literacy scale. Learning and Individual Differences, 41, 79-85. doi:10.1016/j.lindif.2015.06.001

Marsh, H. W., Hau, K.-T., \& Wen, Z. (2004). In search of golden rules: Comment on hypothesistesting approaches to setting cutoff values for fit indexes and dangers in overgeneralizing $\mathrm{Hu}$ and Bentler's (1999) findings. Structural Equation Modeling: A Multidisciplinary Journal, 11(3), 320-341. doi:10.1207/s15328007sem1103_2

Mason L., Junyent A. A., \& Tornatora M. C. (2014). Epistemic evaluation and comprehension of web-source information on controversial science-related topics: Effects of a short-term instructional intervention. Computers \& Education, 76, 143-157.

Metzger, M.J. (2007). Making sense of credibility on the web: Models for evaluating online information and recommendations for future research. Journal of the Association of Information Science and Technology, 58(13), 2078--2091.

Metzger, M.J., \& Flanagin, A.J. (2013). Credibility and trust of information in online environments: The use of cognitive heuristics. Journal of Pragmatics, 59, 201-220.

Norwegian Centre for ICT in Education (2017). Elevene skal kunne bruke og vurdere ulike kilder i arbeid med fag [The students are expected to use and evaluate different sources in their school work]. Retrieved 7 March 2017 from http://www.iktplan.no/index.php?pageID=69\&lang=nb.

Norwegian Directorate for Education and Training. (2012). Framework for basic skills. Oslo:

Norwegian Directorate for Education and Training. Retrieved from http://www.udir.no/Stottemeny/English/Curriculum-in-English/_english/Framework-forBasic-Skills/ Accessed 10.01.2016.

Norwegian Ministry of Education and Research. (2006). Læreplan for den 13-årige grunnopplæringa (K-06) [The national curriculum for primary and secondary education]. Oslo: Government Administration Services. 
Organisation for Economic Co-operation and Development. (2014). TALIS 2013 results: An international perspective on teaching and learning. Paris: OECD Publishing.

Puustinen, M., \& Rouet, J.-R. (2009). Learning with new technologies: Help seeking and information searching revisited. Computers \& Education, 53, 1014-1019.

Sáinz, M., \& Eccles, J. (2012). Self-concept of computer and math ability: Gender implications across time and within ICT studies. Journal of Vocational Behavior, $80,486-499$.

Scherer, R., \& Siddiq, F. (2015). Revisiting teachers' computer self-efficacy: A differentiated view on gender differences. Computers in Human Behavior, 53, 4857. doi: 10.1016/j.chb.2015.06.038

Skaalvik, E. M., \& Skaalvik, S. (2010). Teacher self-efficacy and teacher burnout: A study of relations. Teaching and Teacher Education, 26, 1059-1069.

So, H. -J., Choi, H., Lim, W. Y., \& Xiong, Y. (2012). Little experience with ICT: Are they really the Net Generation student-teachers? Computers \& Education, 59, 12341245. doi: 10.1016/j.compedu.2012.05.008

Teo, T. (2011). Factors influencing teachers' intention to use technology: Model development and test. Computers \& Education, 57(4), 2432-2440.

Tondeur, J., Hermans, R., van Brak, J., \& Valcke, M. (2008). Exploring the link between teachers' educational belief profiles and different types of computer use in the classroom. Computers in Human Behavior, 24(6), 2541-2553.

Tondeur, J., van Braak, J., Sang, G., Voogt, J., Fisser, P., \& Ottenbreit-Leftwich, A. (2012). Preparing preservice teachers to integrate technology in education: A synthesis of qualitative evidence. Computers \& Education, 59, 134-144.

Tondeur, J., Aesaert, K., Pynoo, B., van Braak, J., Fraeyman, N., \& Erstad, O. (2015). Developing a validated instrument to measure preservice teachers' ICT competencies: Meeting the demands of the $21^{\text {st }}$ century. British Journal of Educational Technology, 48(2), 462-472. doi:10.1111/bjet.12380

Viel-Ruma, K., Houchins, D., Jolivette, K., \& Benson, G. (2010). Efficacy beliefs of special educators: The relationships among collective efficacy, teacher self-efficacy, and job satisfaction. Teacher Education and Special Education: The Journal of the 
Teacher Education Division of the Council for Exceptional Children, 33(3), 225233. doi:10.1177/0888406409360129.

Volman, M., van Eck, E., Heemskerk, I., \& Kuiper, E. (2005). New technologies, new differences. Gender and ethnic differences in pupils' use of ICT in primary and secondary education. Computers \& Education, 45(1), 35-55. doi:10.1016/j.compedu.2004.03.001

Walraven, A., Brand-Gruwel, S., \& Boshuizen, H. P. A. (2009). How students evaluate information and sources when searching the World Wide Web for information. Computers \& Education, 52, 234-246.

Walraven, A., Brand-Gruwel, S., \& Boshuizen, H.P.A. (2013). Fostering students' evaluation behaviour while searching the internet. Instr Sci, 41, 125. doi:10.1007/s11251-012-9221-x

Wastiau, P, Blamire, R., Kearney, C., Quittre, V., Van de Gaer, E., \& Monseur, C. (2013). The Use of ICT in Education: A survey of schools in Europe. European Journal of Education, Part I, 48(1), 11-27. Doi:10.1111/ejed.12020

Yang, H. L., \& Cheng, H. H. (2009). Creative self-efficacy and its factors: An empirical study of information system analysts and programmers. Computers in Human Behavior, 25(2), 429-438. doi:10.1016/j.chb.2008.10.005.

Yu, C. Y. (2002). Evaluating cutoff criteria of model fit indices for latent variable models with binary and continuous outcomes. Dissertation submitted to the University of California, LA. 
Tables

Table 1

Hypothesised relations between teachers' use of ICT, ICT self-efficacy for instructional purposes, collegial collaboration and fostering students' evaluation of digital information.

Hypothesis 1 (H1) The of ICT is positively related to ICT self-efficacy for instructional purposes.

Hypothesis $2(\mathrm{H} 2) \quad$ The use of ICT is positively related to fostering students' evaluation of digital information.

Hypothesis 3 (H3) ICT self-efficacy for instructional purposes is positively related to fostering students' evaluation of digital information.

Hypothesis 4 (H4) ICT self-efficacy for instructional purposes is positively related to collegial collaboration.

Hypothesis 5 (H5) The use of ICT is positively related to collegial collaboration.

Hypothesis 6 (H6) Collegial collaboration is positively related to fostering students' evaluation of digital information. 
Table 2

Means, standard deviations, medians, skewness, kurtosis, and factor loadings for all items of the administered scales

\begin{tabular}{llllll}
\hline Scale Items & $M(S D)$ & $M d n$ & Skewness & $\begin{array}{c}\text { Kurtosis } \\
\begin{array}{c}\text { Standardized factor } \\
\text { loadings }(S E)\end{array}\end{array}$ \\
\hline
\end{tabular}

Use of ICT for the following practice (Cronbach's $\alpha=0.79$ )

\begin{tabular}{|c|c|c|c|c|c|}
\hline Presenting information through direct class instruction & $2.34(0.56)$ & 2 & -0.10 & -0.73 & $.48(.04)^{* *}$ \\
\hline Providing remedial or enrichment support & $1.93(0.58)$ & 2 & 0.01 & -0.09 & $.58(.03)^{* *}$ \\
\hline $\begin{array}{l}\text { Enabling student-led whole-class discussions and } \\
\text { presentations }\end{array}$ & $1.76(0.62)$ & 2 & 0.21 & -0.59 & $.60(.03)^{* *}$ \\
\hline Assessing students' learning through tests & $1.87(0.65)$ & 2 & 0.13 & -0.66 & $.59(.03)^{* *}$ \\
\hline Providing feedback to students & $2.11(0.70)$ & 2 & -0.16 & -0.96 & $.55(.04)^{* *}$ \\
\hline $\begin{array}{l}\text { Reinforcing learning of skills through repetition of } \\
\text { examples }\end{array}$ & $1.90(0.58)$ & 2 & 0.01 & -0.12 & $.63(.03)^{* *}$ \\
\hline Supporting collaboration among students & $1.62(0.61)$ & 2 & 0.42 & -0.66 & $.66(.03)^{* *}$ \\
\hline
\end{tabular}

ICT self-efficacy for instructional purposes: How well can you ... (Cronbach's $\alpha=0.68)$

\begin{tabular}{|c|c|c|c|c|c|}
\hline Monitoring students' progress & $1.71(0.45)$ & 2 & -0.95 & -1.11 & $.81(.05)^{* *}$ \\
\hline Preparing lessons that involve the use of ICT by students & $1.90(0.30)$ & 2 & -2.62 & 4.87 & $.73(.04)^{* *}$ \\
\hline Assessing student learning & $1.78(0.42)$ & 2 & -1.33 & -0.23 & $.94(.04)^{* *}$ \\
\hline
\end{tabular}

Collegial collaboration when using ICT in teaching and learning (Cronbach's $\alpha=0.71$ ) 


$\begin{array}{llllll}\text { I work together with other teachers } & 2.50(0.71) & 3 & -0.05 & -0.25 & .69(.04)^{* * *} \\ \text { I systematically collaborate with colleagues to develop } & 2.16(0.70) & 2 & 0.48 & 0.45 & .75(.04)^{* *}\end{array}$

Fostering students' evaluation of digital information (Cronbach's $\alpha=0.89$ )

Evaluating the relevance of digital information

Evaluating the credibility of digital information

Validating the accuracy of digital information

Exploring a range of digital resources

$\begin{array}{lllll}2.82(0.82) & 3 & -0.49 & -0.14 & .81(.02)^{* *} \\ 2.87(0.86) & 3 & -0.56 & -0.20 & .84(.02)^{* *} \\ 2.73(0.86) & 3 & -0.43 & -0.37 & .88(.02)^{* *} \\ 2.50(0.88) & 3 & -0.17 & -0.71 & .73(.03)^{* *}\end{array}$

Note. $* * p<.01$ 


\section{Table 3}

Gender, age and teachers agree about fostering students' evaluation of digital information

\begin{tabular}{|c|c|c|}
\hline Type & & $\%$ \\
\hline \multicolumn{3}{|c|}{ Gender } \\
\hline & Male & 36.4 \\
\hline & Female & 63.6 \\
\hline \multicolumn{3}{|l|}{ Age } \\
\hline & Less than 25 & 1.6 \\
\hline & $25-29$ & 8.8 \\
\hline & $30-39$ & 30.1 \\
\hline & $40-49$ & 27.3 \\
\hline & $50-59$ & 19.3 \\
\hline \multicolumn{3}{|c|}{ Fostering students' evaluation of digital information } \\
\hline & Evaluating the relevance of digital information & 71 \\
\hline & Evaluating the credibility of digital information & 72 \\
\hline & Validating the accuracy of digital information & 66 \\
\hline & Exploring a range of digital resources & 54 \\
\hline
\end{tabular}


Table 4

Correlation matrix for all constructs and gender

\begin{tabular}{|c|c|c|c|c|c|}
\hline Variables & 1. & 2. & 3. & 4. & 5 . \\
\hline 1. ICT use & - & & & & \\
\hline 2. Collegial collaboration & $.45^{* *}$ & - & & & \\
\hline 3. ICT self-efficacy for instructional purposes & $.50 * *$ & $.30 * *$ & - & & \\
\hline 4. Fostering evaluation of online information & $.57 * *$ & $.27 * *$ & $.40 * *$ & - & \\
\hline 5. Gender & .01 & .05 & -.06 & $-.09 * *$ & - \\
\hline
\end{tabular}

Note. $* p<.05, * * p<.01$ 